\title{
The Aquatic Real-Time Monitoring Network: In-Situ Optical Sensors for Monitoring the Nation's Water Quality
}

Floods, hurricanes, and longer-term changes in climate and land use can have profound effects on water quality due to shifts in hydrologic flow paths, water residence time, precipitation patterns, connectivity between rivers and uplands, and many other factors. In order to understand and respond to changes in hydrology and water quality, resource managers and policy makers have a need for accurate and early indicators, as well as the ability to assess possible mechanisms and likely outcomes. In-situ optical sensors - those making continuous measurements of constituents by absorbance or fluorescence properties in the environment at timescales of minutes to years - have a long history in oceanography for developing highly resolved concentrations and fluxes, but are not commonly used in freshwater systems. The United States Geological Survey (USGS) has developed the Aquatic Real-Time Monitoring Network, with high-resolution optical data collection for organic carbon, nutrients, and sediment in large coastal rivers, along with continuous measurements of discharge, water temperature, and dissolved inorganic carbon. The collecting of continuous water-quality data in the Nation's waterways has revealed temporal trends and spatial patterns in constituents that traditional sampling approaches fail to capture, and will serve a critical role in monitoring, assessment and decision-making in a rapidly changing landscape.

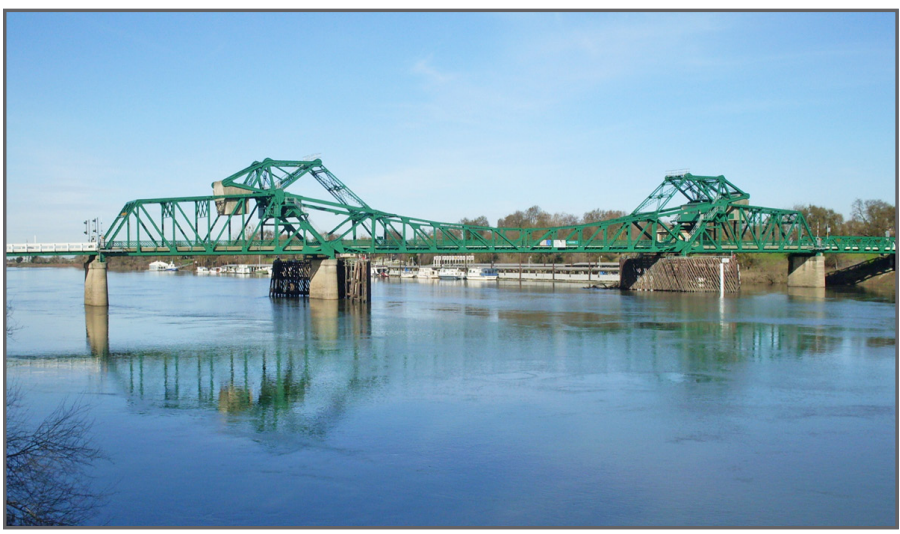

Four sites that represent a distribution of geographic, hydrologic and climatic settings, a 40+ year history of USGS water-quality and discharge data, and important downstream estuaries were instrumented in 2010 for continuous data collection. Future efforts will expand both the number of large coastal rivers being monitored, and also increase the number of parameters to include nitrate, carbon dioxide, and sediment concentrations.

\section{Introduction}

The recent advent of commercially available in-situ optical sensors and data platforms-together with new techniques for data analysis-provides the opportunity to monitor water quality on the time scales in which changes occur. In particular, these measurements are effective sentinels of water-quality changes when coupled with real-time streamflow and climate data. For example, measurements that capture the variability in freshwater systems over time help to assess how shifts in seasonal runoff, changes in precipitation intensity, and increased frequencies of disturbances, such as fire and insect outbreaks, affect the storage, production, and transport of carbon and nitrogen in watersheds. Real-time sensors also provide tools for early trend detection, help identify monitoring gaps, and ensure timely data for science-based decision support across a range of issues related to water quality, freshwater ecosystems, and human health.

\section{The Aquatic Real-Time Monitoring Network}

The goal of the USGS Aquatic Real-Time (ART) Monitoring Network is to link the changing biogeochemistry of landscapes and the drivers of constituent transport from large rivers across space and time through an inter-calibrated network of real-time sensors. Dissolved organic carbon (DOC) plays an important role in watersheds through constituent transport, energy for foodwebs, and effects on drinking-water quality. In addition, accurate fluxes of DOC and dissolved inorganic carbon (DIC) are critical for global and regional carbon budgets. Therefore, the first major step-ART-Carbon-focuses on the scientific value of an inter-calibrated network of sensors to measure carbon fluxes at key USGS gaging stations in large rivers across the country.

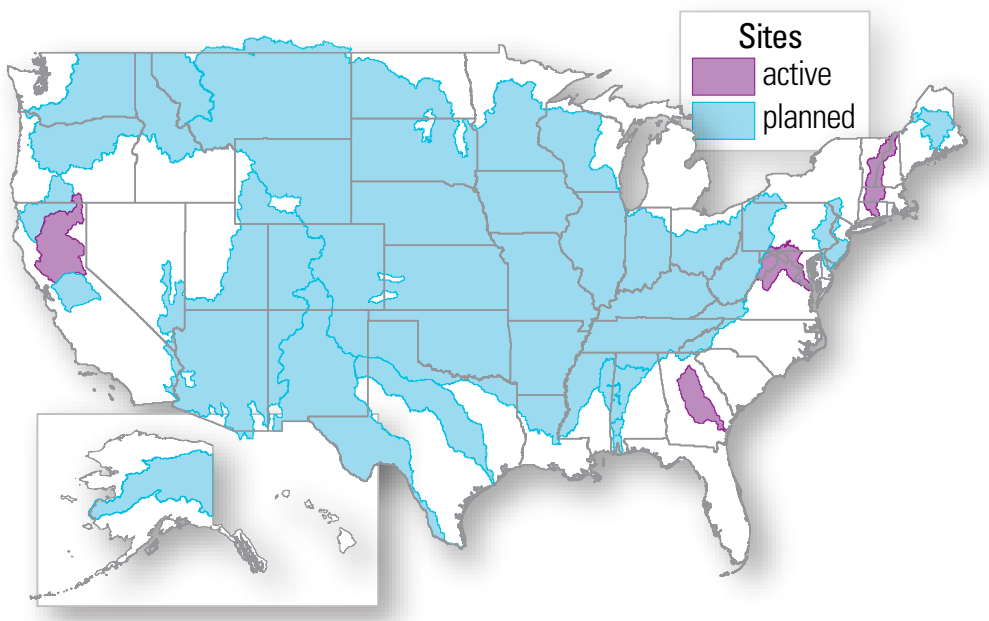




\section{What can we learn from the ART Network in large coastal basins?}

The myriad effects of climate and land-use change are integrated locally by small watersheds and regionally by large ones. High-frequency data allow for observation of changes at the rate at which they occur-for example, changes in carbon flux related to storms, seasonal transitions, and snowmelt. A network of high-frequency carbon sensors in sentinel watersheds and larger river basins nationwide could provide information about changes in terrestrial carbon fluxes, sources of sediments, hydrologic flow paths, aquatic productivity, and the transport of terrestrial productivity to the ocean. More importantly, key links to biological, hydrological, and ecological data could be established, along with groundtruthing of space-based observations and validation data for global and regional models.

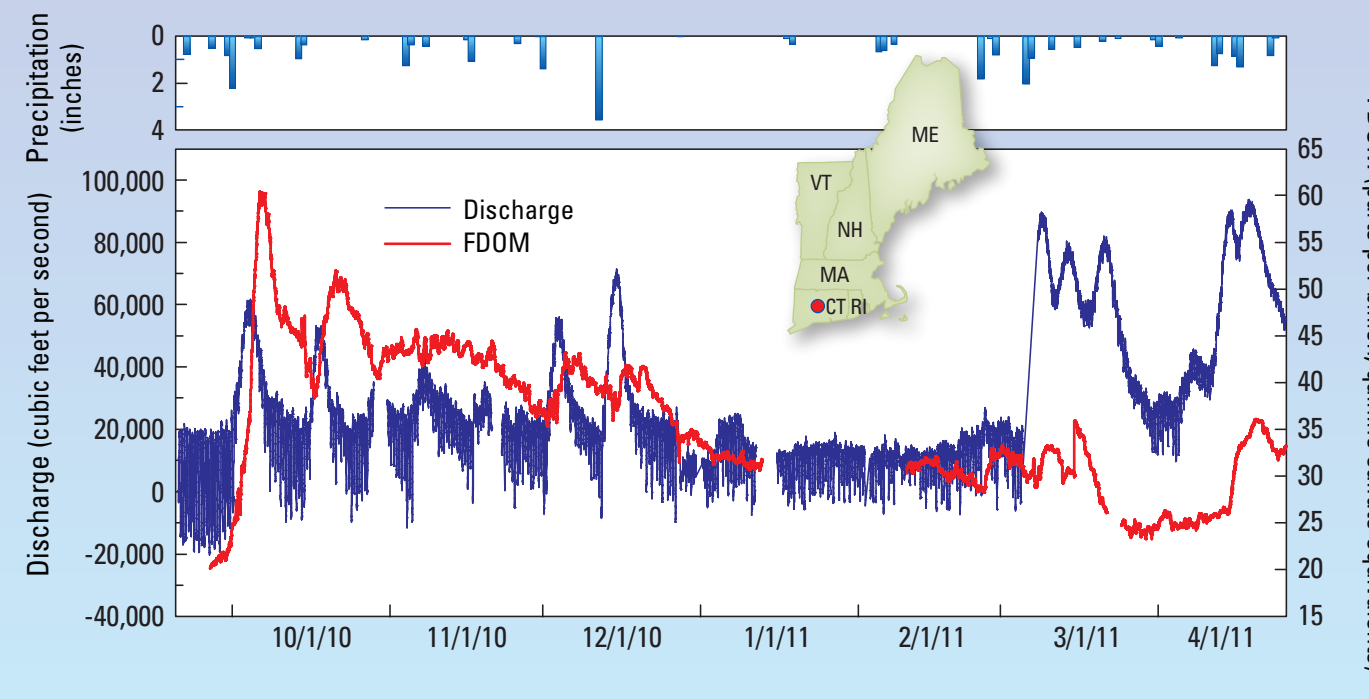

$\begin{array}{ll} & \text { Discharge and dissolved } \\ \text { organic matter } \\ \text { fluorescence (FDOM) from } \\ \text { the Connecticut River }\end{array}$

\section{Building a USGS Sensor Network}

Building the USGS ART Network relies on the ability to develop and maintain a broad spatial network of sensors, which entails four key components: 1) sensor verification and testing, 2) advanced methods for data acquisition, 3) new approaches for data management, and 4) training of researchers, managers, and field staff. Additional inter-calibrated sites in small watersheds, and focused studies that target regional scale issues of national importance, will allow for improved adaptive management and prediction of carbon, nutrient, and sediment dynamics in the face of climate variability and land-use change.

\section{Long-Term Strategy for the ART Network}

The long-term effect of the ART Monitoring Network will be enhanced through strategic investments in the following areas:

\section{- Expand Coverage to Other Coastal Basins and Key} Inland Sites. The ART Network would benefit from an expansion to additional major coastal basins nationwide, as well as long-term upstream monitoring locations already the focus of USGS programs and collaborations.

- Extend the Network into Estuaries. One of the benefits of continuous monitors is that they are amenable to data collection in the rapidly changing tidal environments of estuaries. Linking river ART stations to the estuaries they supply will permit unprecedented evaluation of biogeochemical and constituenttransport issues in estuaries.

- Improve Capabilities and Tools. Instruments are currently available to significantly improve measurements of nutrients, wastewater contributions, carbon sources, and others. As new measurement technologies become available, they should be evaluated for incorporation into the ART Network.

- Conduct Applied Research. The advances afforded by implementation of the ART Network provide significant opportunities for collaboration with partners to apply the methods and technologies to other water-quality issues.

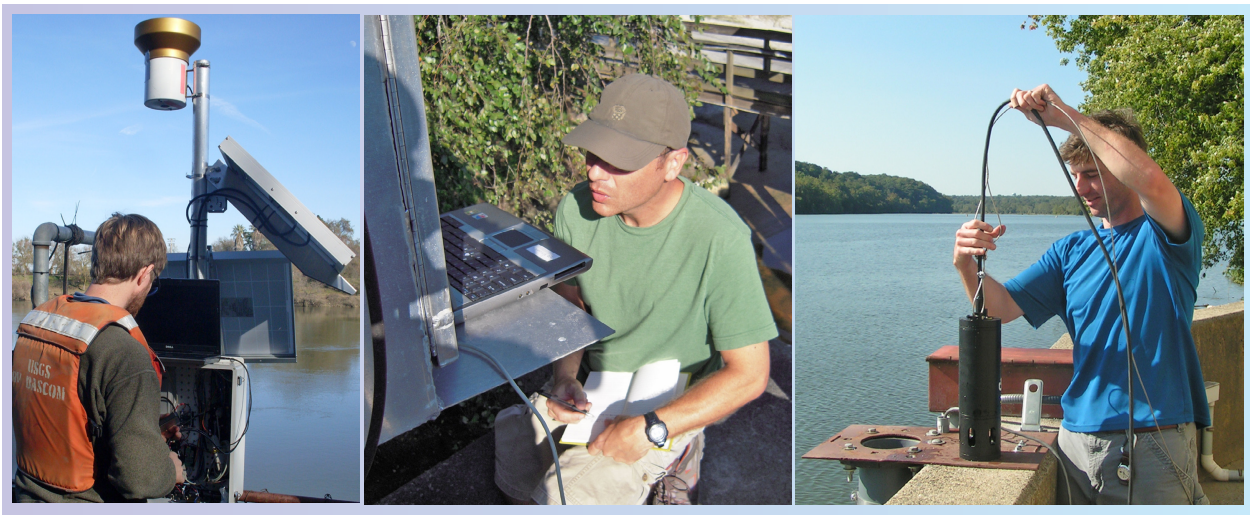

Brian A. Pellerin, Brian A. Bergamaschi, Peter S. Murdoch, Bryan D. Downing, JohnFranco Saraceno, George R. Aiken, and Robert G. Striegl

For more information contact: USGS California Water Science Center 6000 J Street, Placer Hall Sacramento, CA 95819-6129 Phone: (916) 278-3167 http://ca.water.usgs.gov 